\title{
Sub-lethal peak exposure to insecticides triggers olfaction-mediated avoidance in zebrafish larvae
}

Sarah Könemann ${ }^{1,2}$, Stéphanie Meyer ${ }^{2}$, Alexander Betz ${ }^{1}$, Anže Županiči,3, Colette vom Berg ${ }^{1, *}$

${ }^{1}$ Department of Environmental Toxicology, Eawag, Überlandstrasse 133, 8600 Dübendorf, Switzerland

2 École Polytechnique Fédéral de Lausanne, EPFL, Route Cantonale, 1015 Lausanne, Switzerland

${ }^{3}$ Current address: Department of Biotechnology and Systems Biology, National Institute of Biology, Vecna pot 111, 1000

Ljubljana, Slovenia

*Corresponding author: Dr. Colette vom Berg, Email: Colette.vomberg@eawag.ch

17 pages containing 14 figures and 5 tables 


\section{List of the supporting information}

- $\quad$ Figure S1: Results of the dye distribution experiments.

Page S3

- Figure S2: Plot of the simulated diffusion-based distribution of the chemical.

Page S3

- Table S1: Conversion of molar concentrations to mass concentrations.

Page 54

- Figure S3: Turn angle box plots for whole chamber.

Page S4

- $\quad$ Figure S4: Velocity box plots for whole chamber.

Page S4

- Table S2: ANCOVA p values for whole chamber.

Page S5

- $\quad$ Figure S5: Turn angle box plots for chemical zone. Page S6

- $\quad$ Figure S6: Velocity box plots for chemical zone. $\quad$ Page S7

- Table S3: ANCOVA p values for chemical zone. Page S8

- $\quad$ Figure S7: Locomotion of cadmium-exposed zebrafish larvae. $\quad$ Page S8

- $\quad$ Figure S8: Heat map with brain regions (Figure 4 in manuscript). Page S9

- $\quad$ Figure S9: Heat map with brain regions including cadmium-treated fish. Page S10

- $\quad$ Figure S10: Volcano plots based on adjusted p values. $\quad$ Page S11

- $\quad$ Figure S11: Exact position tracking based on triangulation. $\quad$ Page S12

- $\quad$ Figure S12: Histograms used for data inclusion criteria. $\quad$ Page S12

- Table S4: Sample sizes of behavior experiments. Page S13

- Table S5: Sample sizes of the cadmium experiments. $\quad$ Page S14

- Figure S13a: Illustration of coordinate system of the chamber. Page S15

- $\quad$ Figure S13b: Illustration of the zoned defined for the biased random walk model. Page S15

- Methods section: Biased random walk model. $\quad$ Page S16

- $\quad$ Figure S14: Results biased random walk model. $\quad$ Page S17 


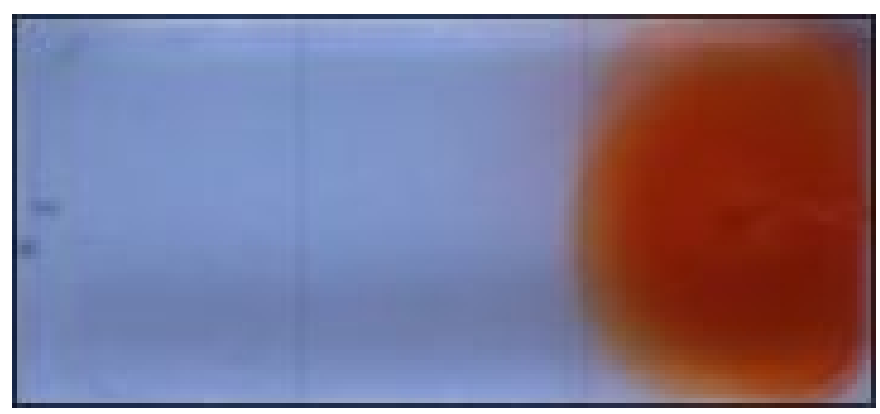

Figure S1: Results of the dye distribution experiment. To visualize how the added chemicals distribute over the duration of the experiment, neutral red dye was added to the chamber under the same conditions (speed, duration) as the chemicals. The substance stays within the zone where it was added, which will further be referred to as "chemical zone". The figure shows an overlay of five images taken three minutes after the addition of the dye.

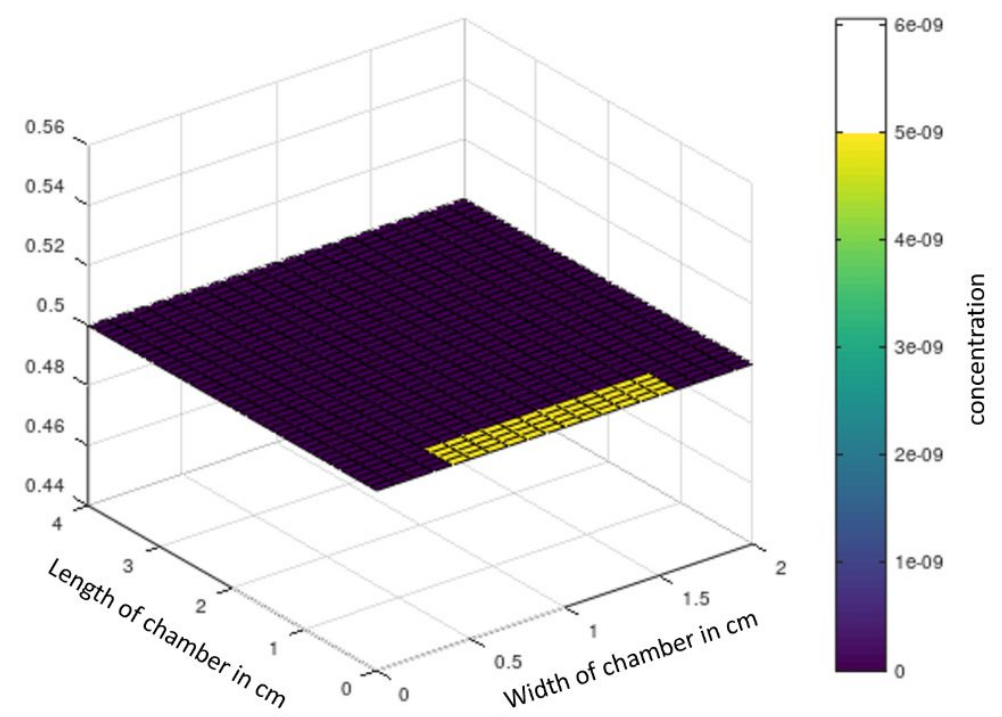

Figure S2: Simulated diffusion-based distribution of the tested chemicals in the behaviour chamber until three minutes after the injection of the stimulus.

Table S1: Conversion of molar concentrations to mass concentrations using the molecular weight of the chemicals.

\begin{tabular}{lllllll}
\hline $\begin{array}{l}\text { Concentration } \\
\text { in } \mu \mathrm{mol} / \mathrm{L}\end{array}$ & \multicolumn{5}{c}{ Concentration in $\mathrm{mg} / \mathrm{L}$} \\
& Diazinon & Dimethoate & Imidacloprid & Thiacloprid & Pirimicarb & Methomyl \\
\cline { 2 - 7 } $\mathbf{0 . 1}$ & 0.030435 & 0.02292 & 0.025566 & 0.025272 & 0.023829 & 0.016221 \\
$\mathbf{1}$ & 0.30435 & 0.2292 & 0.25566 & 0.25272 & 0.23829 & 0.16221 \\
$\mathbf{1 0}$ & 3.0435 & 2.292 & 2.5566 & 2.5272 & 2.3829 & 1.6221 \\
$\mathbf{1 0 0}$ & 30.435 & 22.92 & 25.566 & 25.272 & 23.829 & 16.221 \\
\hline
\end{tabular}


Dimethoate

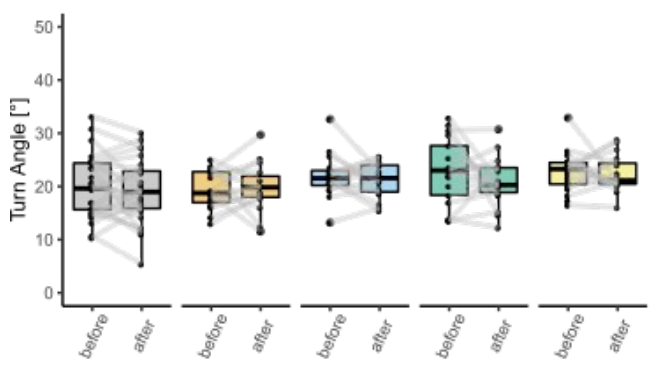

官 $0 \mu \mathrm{M}$ 官 $0.1 \mu \mathrm{M}$ 官 $1 \mu \mathrm{M}$ 官 $10 \mu \mathrm{M}$ 官 $100 \mu \mathrm{M}$

Thiacloprid

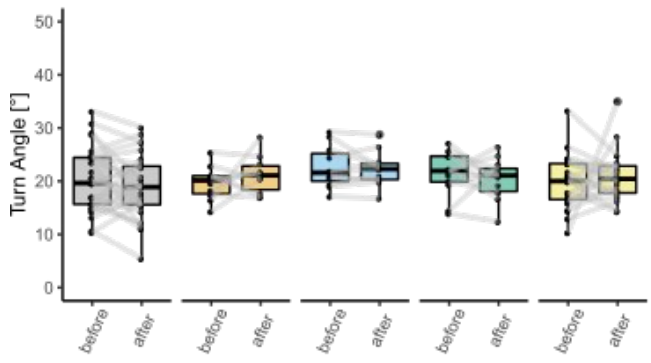

官 $0 \mu \mathrm{M}$ 官 $0.1 \mu \mathrm{M}$ 官 $1 \mu \mathrm{M}$ 官 $10 \mu \mathrm{M}$ 官 $100 \mu \mathrm{M}$
Pirimicarb

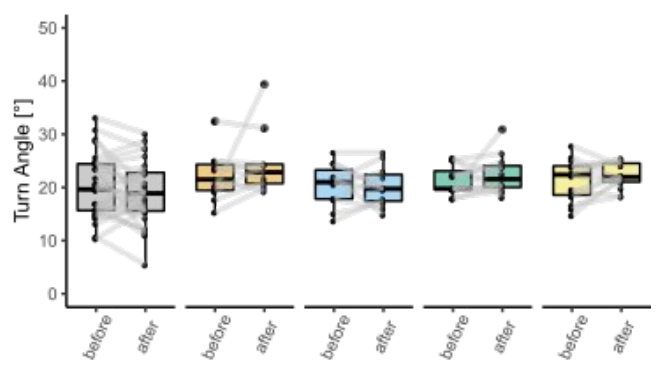

官 $0 \mu \mathrm{M}$ 官 $0.1 \mu \mathrm{M}$ 官 $1 \mu \mathrm{M}$ 官 $10 \mu \mathrm{M}$ 官 $100 \mu \mathrm{M}$

Methomyl

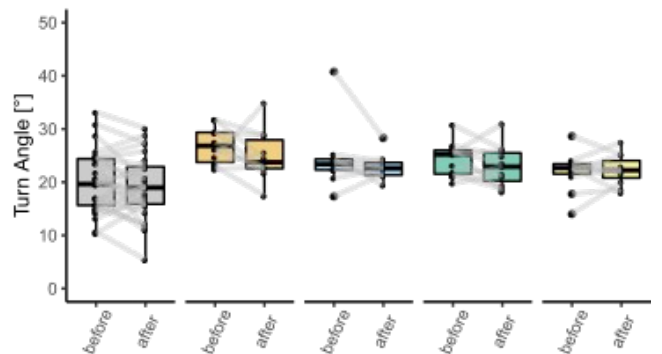

官 $0 \mu \mathrm{M}$ 官 $0.1 \mu \mathrm{M}$ 官 $1 \mu \mathrm{M}$ 官 $10 \mu \mathrm{M}$ 官 $100 \mu \mathrm{M}$

Figure S3: Mean turn angle in degree in the whole chamber before and after the injection of the chemical.

Dimethoate

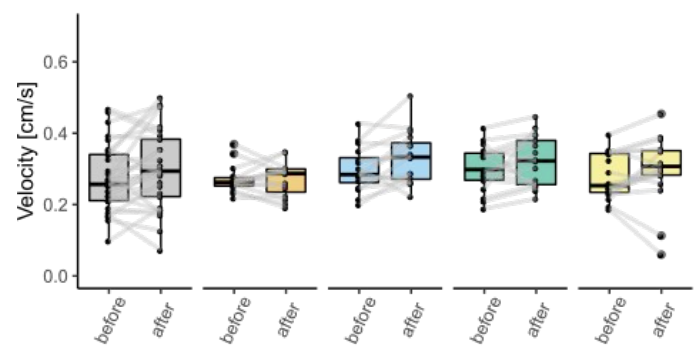

追 $0 \mu \mathrm{M}$ 穴 $0.1 \mu \mathrm{M}$ 追 $1 \mu \mathrm{M}$ 追 $10 \mu \mathrm{M}$ 官 $100 \mu \mathrm{M}$

Thiacloprid

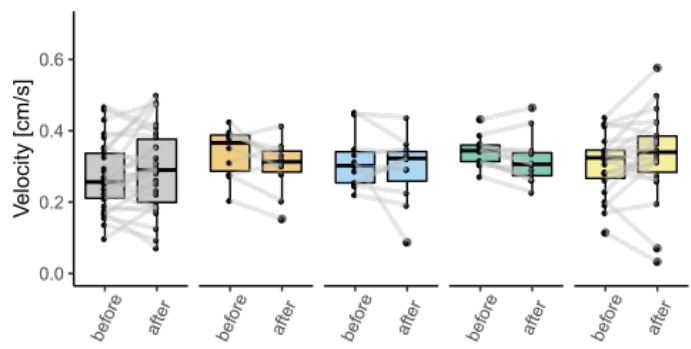

官 $0 \mu \mathrm{M}$ 官 $0.1 \mu \mathrm{M}$ 官 $1 \mu \mathrm{M}$ 官 $10 \mu \mathrm{M}$ 官 $100 \mu \mathrm{M}$
Pirimicarb

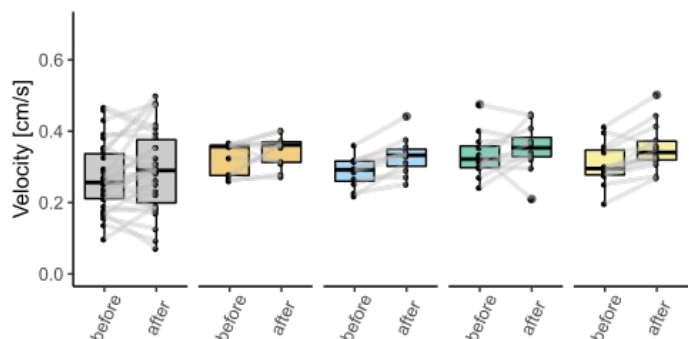

白 $0 \mu \mathrm{M}$ 它 $0.1 \mu \mathrm{M}$ 官 $1 \mu \mathrm{M}$ 追 $10 \mu \mathrm{M}$ 官 $100 \mu \mathrm{M}$

Methomyl

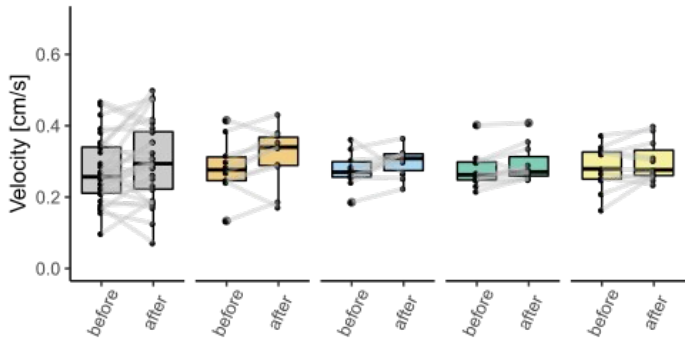

追 $0 \mu \mathrm{M}$ 它 $0.1 \mu \mathrm{M}$ 官 $1 \mu \mathrm{M}$ 官 $10 \mu \mathrm{M}$ 官 $100 \mu \mathrm{M}$

Figure S4: Mean velocity in $\mathrm{cm}$ per second in the whole chamber before and after the injection of the chemical. 
Table S2: Results of the ANCOVA with Dunnett's post-hoc test used to evaluate statistical difference between treatments and control for swimming velocity and turn angle size in the whole chamber.

\begin{tabular}{|c|c|c|c|c|c|}
\hline & Velocity & & Turn angle & & Comparisons \\
\hline Chemical & ANCOVA (p-value) & Dunnett's & ANCOVA ( $p$-value) & Dunnett's & \\
\hline \multirow[t]{4}{*}{ Imidacloprid } & 0.557 & & 0.05 & 0.097 & $0.1 \mu \mathrm{M}$ vs $0 \mu \mathrm{M}$ \\
\hline & & & & 0.171 & $1 \mu \mathrm{M}$ vs $0 \mu \mathrm{M}$ \\
\hline & & & & 0.213 & $10 \mu \mathrm{M}$ vs $0 \mu \mathrm{M}$ \\
\hline & & & & 0.034 & $100 \mu \mathrm{M}$ vs $0 \mu \mathrm{M}$ \\
\hline \multirow[t]{4}{*}{ Diazinon } & 0.38 & & 0.017 & 0.154 & $0.1 \mu \mathrm{M}$ vs $0 \mu \mathrm{M}$ \\
\hline & & & & 1 & $1 \mu \mathrm{M}$ vs $0 \mu \mathrm{M}$ \\
\hline & & & & 0.953 & $10 \mu \mathrm{M}$ vs $0 \mu \mathrm{M}$ \\
\hline & & & & 0.006 & $100 \mu \mathrm{M}$ vs $0 \mu \mathrm{M}$ \\
\hline \multirow[t]{4}{*}{ Methomyl } & 0.969 & & 0.46 & & $0.1 \mu \mathrm{M}$ vs $0 \mu \mathrm{M}$ \\
\hline & & & & & $1 \mu \mathrm{M}$ vs $0 \mu \mathrm{M}$ \\
\hline & & & & & $10 \mu \mathrm{M}$ vs $0 \mu \mathrm{M}$ \\
\hline & & & & & $100 \mu \mathrm{M}$ vs $0 \mu \mathrm{M}$ \\
\hline \multirow[t]{4}{*}{ Dimethoate } & 0.568 & & 0.601 & & $0.1 \mu \mathrm{M}$ vs $0 \mu \mathrm{M}$ \\
\hline & & & & & $1 \mu \mathrm{M}$ vs $0 \mu \mathrm{M}$ \\
\hline & & & & & $10 \mu \mathrm{M}$ vs $0 \mu \mathrm{M}$ \\
\hline & & & & & $100 \mu \mathrm{M}$ vs $0 \mu \mathrm{M}$ \\
\hline \multirow[t]{4}{*}{ Thiacloprid } & 0.045 & 0.101 & 0.298 & & $0.1 \mu \mathrm{M}$ vs $0 \mu \mathrm{M}$ \\
\hline & & 0.328 & & & $1 \mu \mathrm{M}$ vs $0 \mu \mathrm{M}$ \\
\hline & & 0.288 & & & $10 \mu \mathrm{M}$ vs $0 \mu \mathrm{M}$ \\
\hline & & 1 & & & $100 \mu \mathrm{M}$ vs $0 \mu \mathrm{M}$ \\
\hline \multirow[t]{4}{*}{ Pirimicarb } & 0.602 & & 0.022 & 0.012 & $0.1 \mu \mathrm{M}$ vs $0 \mu \mathrm{M}$ \\
\hline & & & & 1 & $1 \mu \mathrm{M}$ vs $0 \mu \mathrm{M}$ \\
\hline & & & & 0.13 & $10 \mu \mathrm{M}$ vs $0 \mu \mathrm{M}$ \\
\hline & & & & 0.193 & $100 \mu \mathrm{M}$ vs $0 \mu \mathrm{M}$ \\
\hline \multirow[t]{2}{*}{ TCA } & $5.30 \mathrm{E}-05$ & 0.64 & 0.000114 & 0.00053 & $10 \mathrm{mM}$ vs $0 \mathrm{mM}$ \\
\hline & & $3.50 \mathrm{E}-05$ & & 0.000628 & $100 \mathrm{mM}$ vs $0 \mathrm{mM}$ \\
\hline Imidacloprid_Cd & 0.947 & & 0.84 & & $10 \mu \mathrm{M}$ vs $0 \mu \mathrm{M}$ \\
\hline Diazinon_Cd & 0.32 & & 0.601 & & $10 \mu \mathrm{M}$ vs $0 \mu \mathrm{M}$ \\
\hline TCA_Cd & 0.792 & & 0.229 & & $10 \mathrm{mM}$ vs $0 \mathrm{mM}$ \\
\hline
\end{tabular}




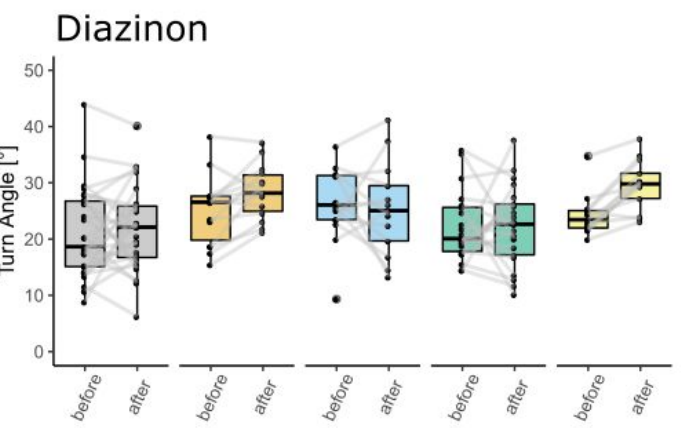

追 $0 \mu \mathrm{M}$ 它 $0.1 \mu \mathrm{M}$ 官 $1 \mu \mathrm{M}$ 官 $10 \mu \mathrm{M}$ 官 $100 \mu \mathrm{M}$

\section{Imidacloprid}

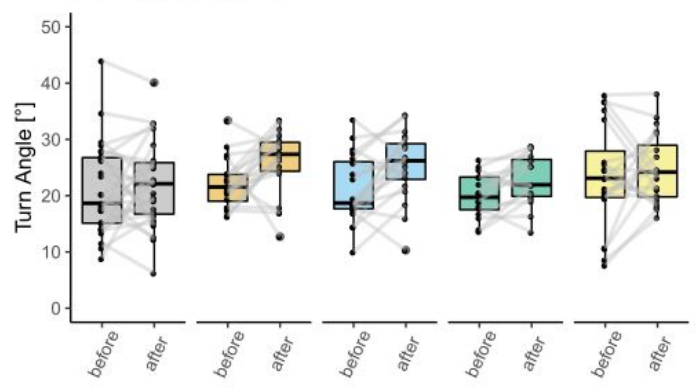

追 $0 \mu \mathrm{M}$ 官 $0.1 \mu \mathrm{M}$ 官 $1 \mu \mathrm{M}$ 官 $10 \mu \mathrm{M}$ 追 $100 \mu \mathrm{M}$

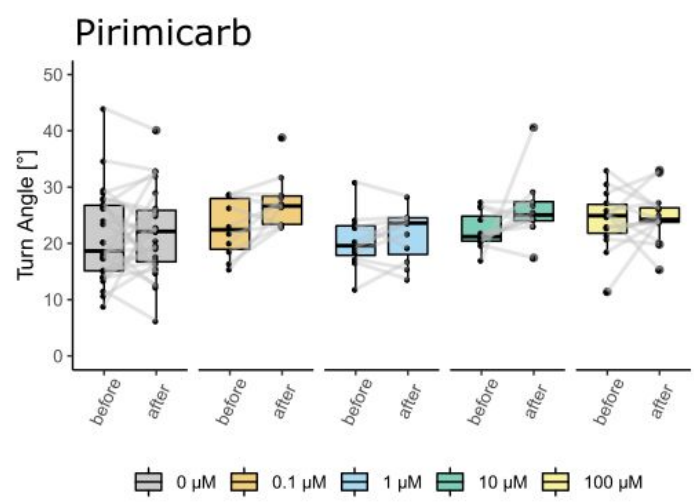

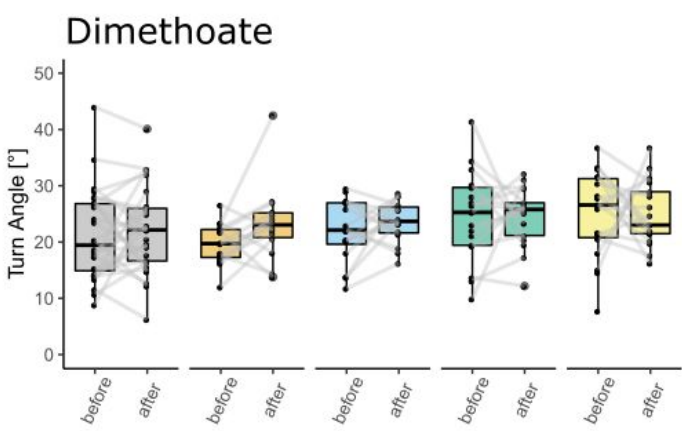

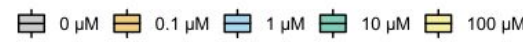

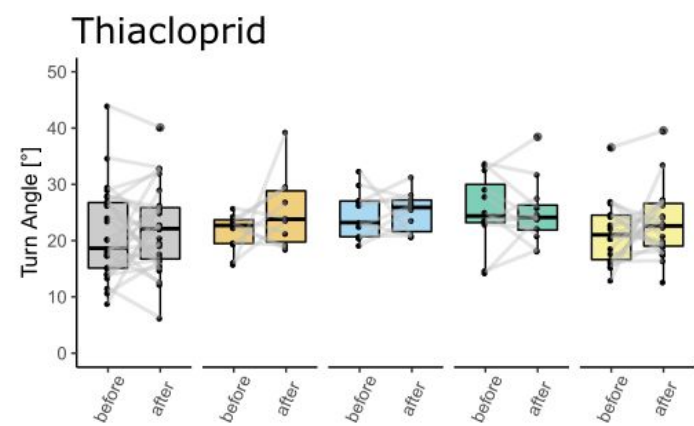

追 $0 \mu \mathrm{M}$ 官 $0.1 \mu \mathrm{M}$ 官 $1 \mu \mathrm{M}$ 官 $10 \mu \mathrm{M}$ 追 $100 \mu \mathrm{M}$

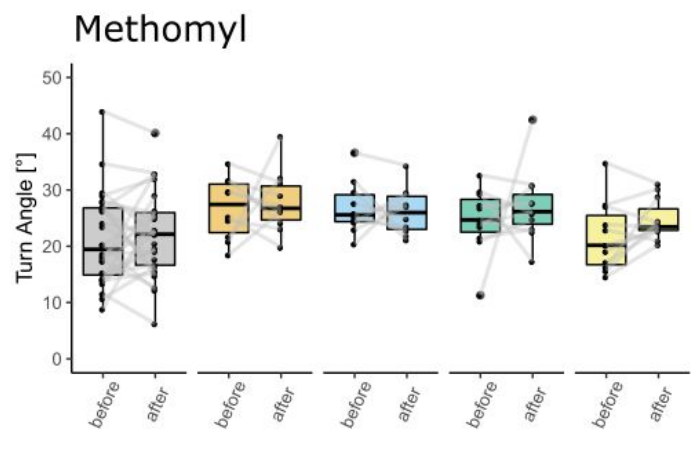

追 $0 \mu \mathrm{M}$ 追 $0.1 \mu \mathrm{M}$ 户 $1 \mu \mathrm{M}$ 它 $10 \mu \mathrm{M}$ 穴 $100 \mu \mathrm{M}$

Figure S5: Mean turn angle in degree in the chemical zone of the chamber before and after the injection of the chemical. 


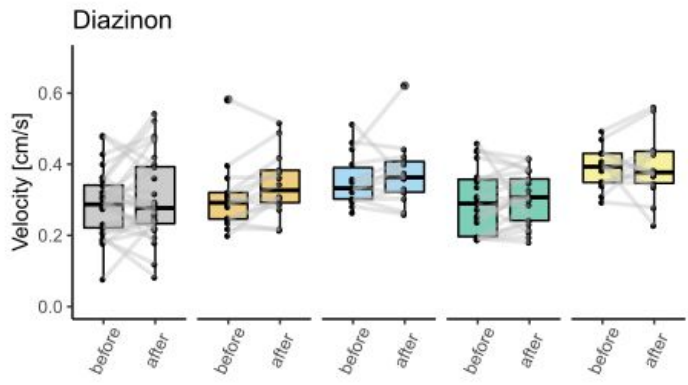

追 $0 \mu \mathrm{M}$ 穴 $0.1 \mu \mathrm{M}$ 官 $1 \mu \mathrm{M}$ 官 $10 \mu \mathrm{M}$ 官 $100 \mu \mathrm{M}$

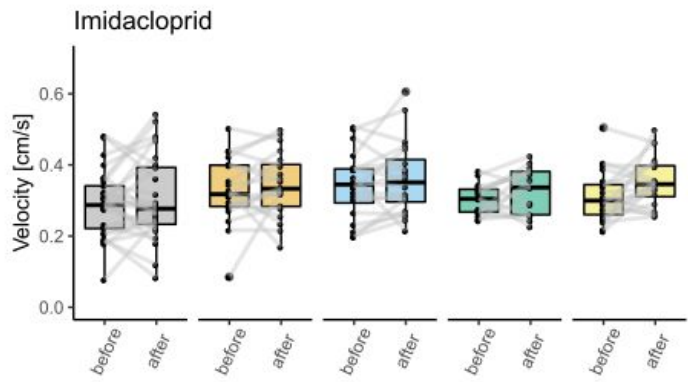

追 $0 \mu \mathrm{M}$ 官 $0.1 \mu \mathrm{M}$ 官 $1 \mu \mathrm{M}$ 官 $10 \mu \mathrm{M}$ 官 $100 \mu \mathrm{M}$

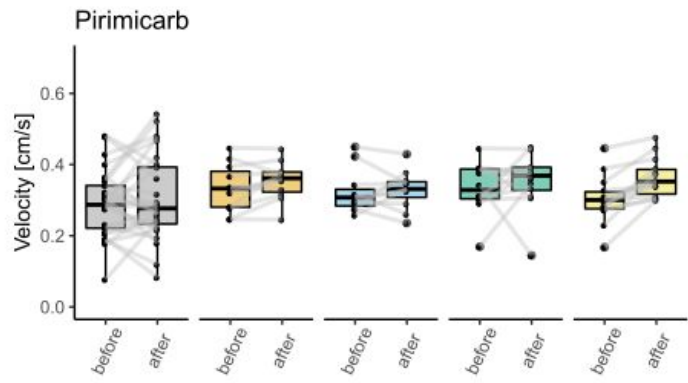

追 $0 \mu \mathrm{M}$ 穴 $0.1 \mu \mathrm{M}$ 官 $1 \mu \mathrm{M}$ 官 $10 \mu \mathrm{M}$ 官 $100 \mu \mathrm{M}$

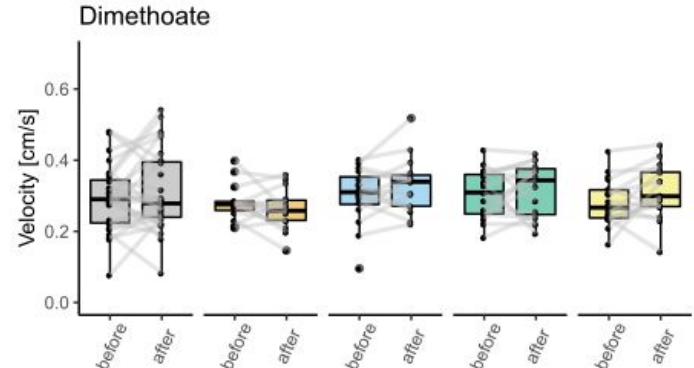

追 $0 \mu \mathrm{M}$ 追 $0.1 \mu \mathrm{M}$ 官 $1 \mu \mathrm{M}$ 官 $10 \mu \mathrm{M}$ 官 $100 \mu \mathrm{M}$

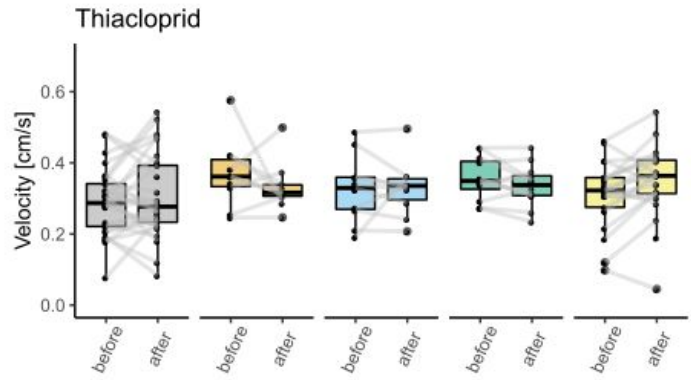

官 $0 \mu \mathrm{M}$ 官 $0.1 \mu \mathrm{M}$ 官 $1 \mu \mathrm{M}$ 官 $10 \mu \mathrm{M}$ 官 $100 \mu \mathrm{M}$

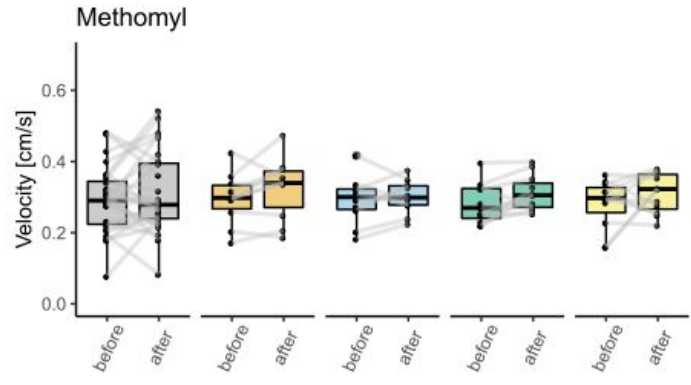

追 $0 \mu \mathrm{M}$ 穴 $0.1 \mu \mathrm{M}$ 官 $1 \mu \mathrm{M}$ 官 $10 \mu \mathrm{M}$ 官 $100 \mu \mathrm{M}$

Figure S6: Mean velocity in $\mathrm{cm}$ per second in the chemical zone of the chamber before and after the injection of the chemical. 
Table S3: Results of the ANCOVA with Dunnett's post-hoc test used to evaluate statistical difference between treatments and control for swimming velocity and turn angle size in the chemical zone.

\begin{tabular}{|c|c|c|c|c|c|}
\hline & Velocity & & Turnangle & & Comparisons \\
\hline Chemical & ANCOVA (p-value) & Dunnett's & ANCOVA ( $p$-value) & Dunnett's & \\
\hline \multirow[t]{4}{*}{ Imidacloprid } & 0.664 & & 0.191 & & $0.1 \mu \mathrm{M}$ vs $0 \mu \mathrm{M}$ \\
\hline & & & & & $1 \mu \mathrm{M}$ vs $0 \mu \mathrm{M}$ \\
\hline & & & & & $10 \mu \mathrm{M}$ vs $0 \mu \mathrm{M}$ \\
\hline & & & & & $100 \mu \mathrm{M}$ vs $0 \mu \mathrm{M}$ \\
\hline \multirow[t]{4}{*}{ Diazinon } & 0.715 & & 0.012 & 0.0356 & $0.1 \mu \mathrm{M}$ vs $0 \mu \mathrm{M}$ \\
\hline & & & & 0.888 & $1 \mu \mathrm{M}$ vs $0 \mu \mathrm{M}$ \\
\hline & & & & 0.85 & $10 \mu \mathrm{M}$ vs $0 \mu \mathrm{M}$ \\
\hline & & & & 0.005 & $100 \mu \mathrm{M}$ vs $0 \mu \mathrm{M}$ \\
\hline \multirow[t]{4}{*}{ Methomyl } & 0.959 & & 0.283 & & $0.1 \mu \mathrm{M}$ vs $0 \mu \mathrm{M}$ \\
\hline & & & & & $1 \mu \mathrm{M}$ vs $0 \mu \mathrm{M}$ \\
\hline & & & & & $10 \mu \mathrm{M}$ vs $0 \mu \mathrm{M}$ \\
\hline & & & & & $100 \mu \mathrm{M}$ vs $0 \mu \mathrm{M}$ \\
\hline \multirow[t]{4}{*}{ Dimethoate } & 0.352 & & 0.487 & & $0.1 \mu \mathrm{M}$ vs $0 \mu \mathrm{M}$ \\
\hline & & & & & $1 \mu \mathrm{M}$ vs $0 \mu \mathrm{M}$ \\
\hline & & & & & $10 \mu \mathrm{M}$ vs $0 \mu \mathrm{M}$ \\
\hline & & & & & $100 \mu \mathrm{M}$ vs $0 \mu \mathrm{M}$ \\
\hline \multirow[t]{4}{*}{ Thiacloprid } & 0.249 & & 0.734 & & $0.1 \mu \mathrm{M}$ vs $0 \mu \mathrm{M}$ \\
\hline & & & & & $1 \mu \mathrm{M}$ vs $0 \mu \mathrm{M}$ \\
\hline & & & & & $10 \mu \mathrm{M}$ vs $0 \mu \mathrm{M}$ \\
\hline & & & & & $100 \mu \mathrm{M}$ vs $0 \mu \mathrm{M}$ \\
\hline \multirow[t]{4}{*}{ Pirimicarb } & 0.293 & & 0.191 & & $0.1 \mu \mathrm{M}$ vs $0 \mu \mathrm{M}$ \\
\hline & & & & & $1 \mu \mathrm{M}$ vs $0 \mu \mathrm{M}$ \\
\hline & & & & & $10 \mu \mathrm{M}$ vs $0 \mu \mathrm{M}$ \\
\hline & & & & & $100 \mu \mathrm{M}$ vs $0 \mu \mathrm{M}$ \\
\hline \multirow[t]{2}{*}{ TCA } & $2.40 \mathrm{E}-02$ & 0.341 & 0.000876 & 0.000377 & $10 \mathrm{mM}$ vs $0 \mathrm{mM}$ \\
\hline & & 0.293 & & 0.628 & $100 \mathrm{mM}$ vs $0 \mathrm{mM}$ \\
\hline Imidacloprid_Cd & 0.157 & & 0.928 & & $10 \mu \mathrm{M}$ vs $0 \mu \mathrm{M}$ \\
\hline Diazinon_Cd & 0.051 & & 0.168 & & $10 \mu \mathrm{M}$ vs $0 \mu \mathrm{M}$ \\
\hline TCA_Cd & 0.211 & & 0.096 & & $10 \mathrm{mM}$ vs $0 \mathrm{mM}$ \\
\hline
\end{tabular}




\section{Cadmium}

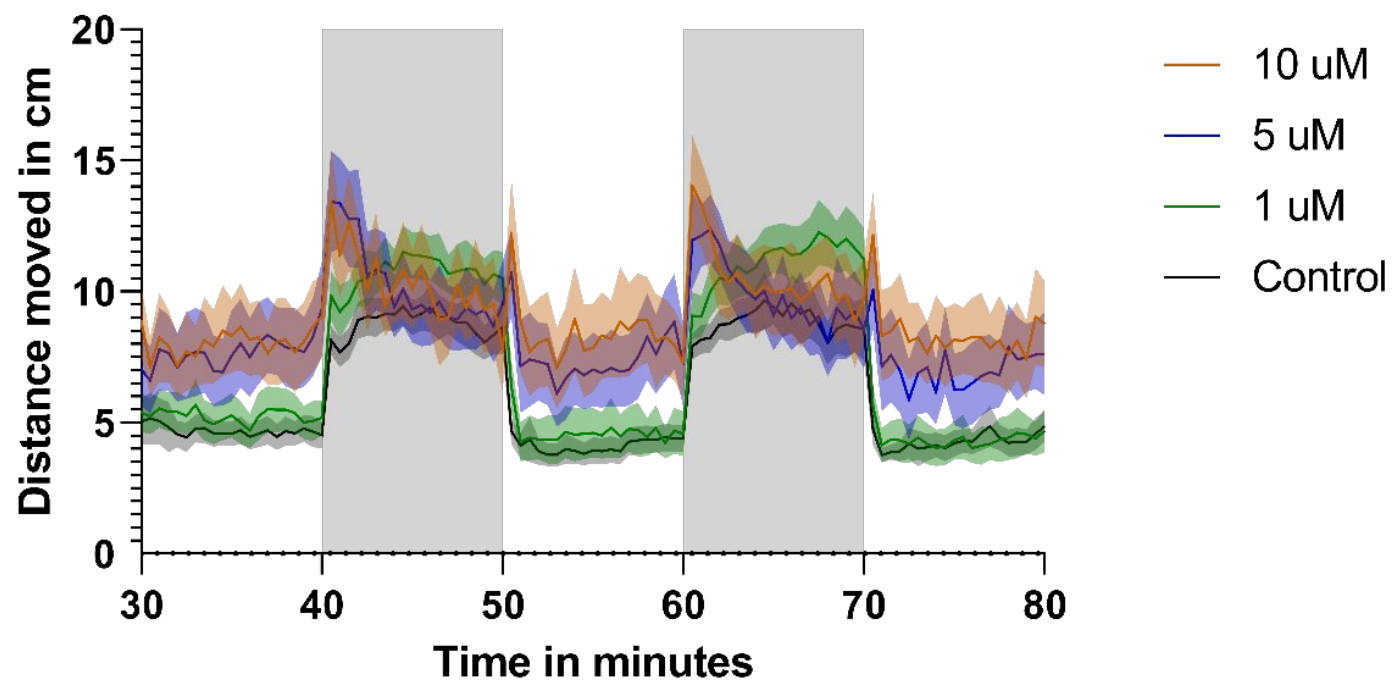

Figure S7: Results of the dark-light transition assay with cadmium-exposed fish. The error bands show the $95 \%$ confidence intervals; periods shaded in gray represent dark periods. Twelve fish were used per concentration. 


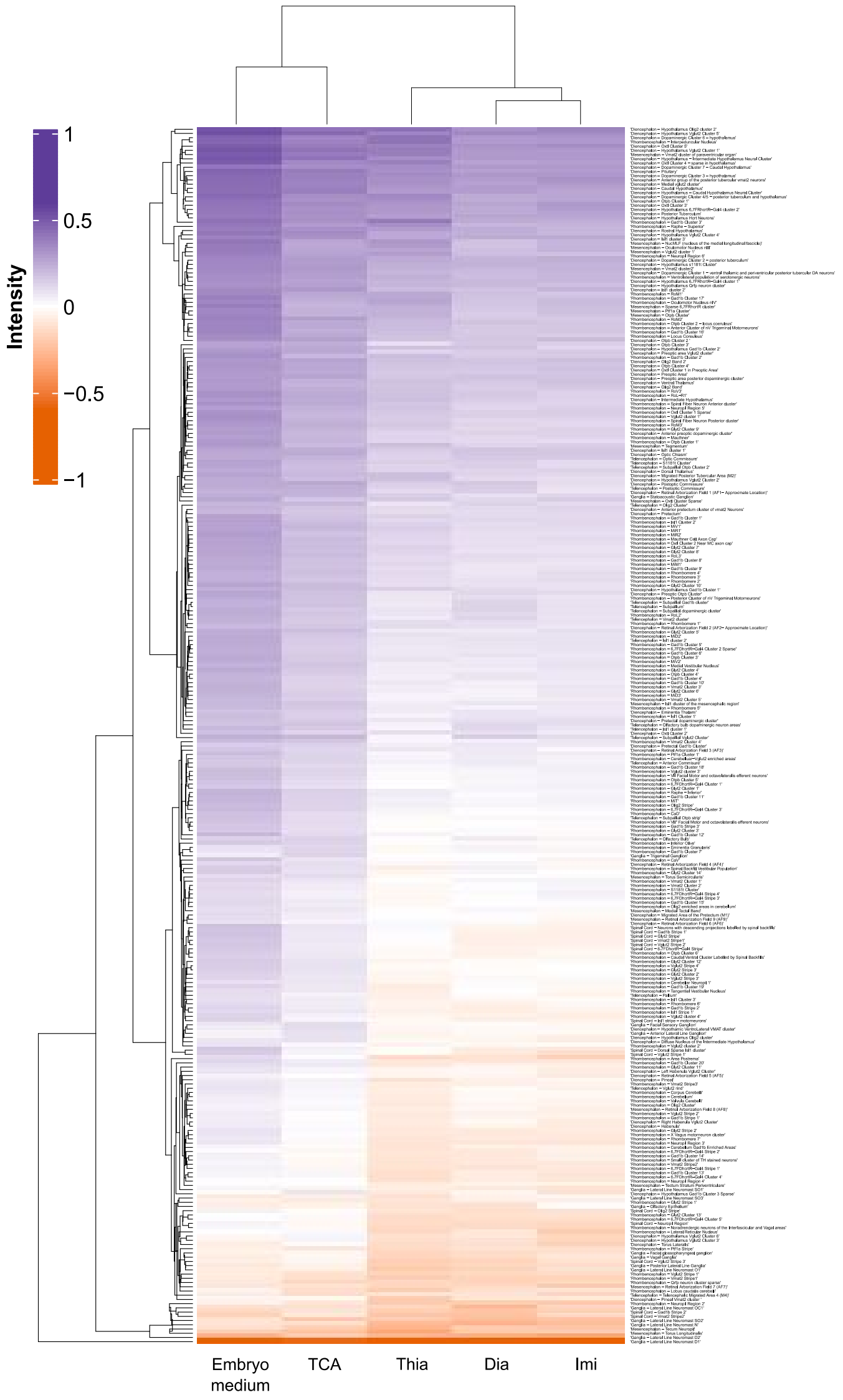

Figure S8: Neuronal activity in the different brain regions during avoidance. The heat map shows the similarities and dissimilarities in neuronal activity of 289 different brain regions for the different treatments embryo medium $(n=14)$, TCA $(n=14)$, diazinon $(n=13)$, and imidacloprid $(n=11)$. Here the names of the brain regions are included. 


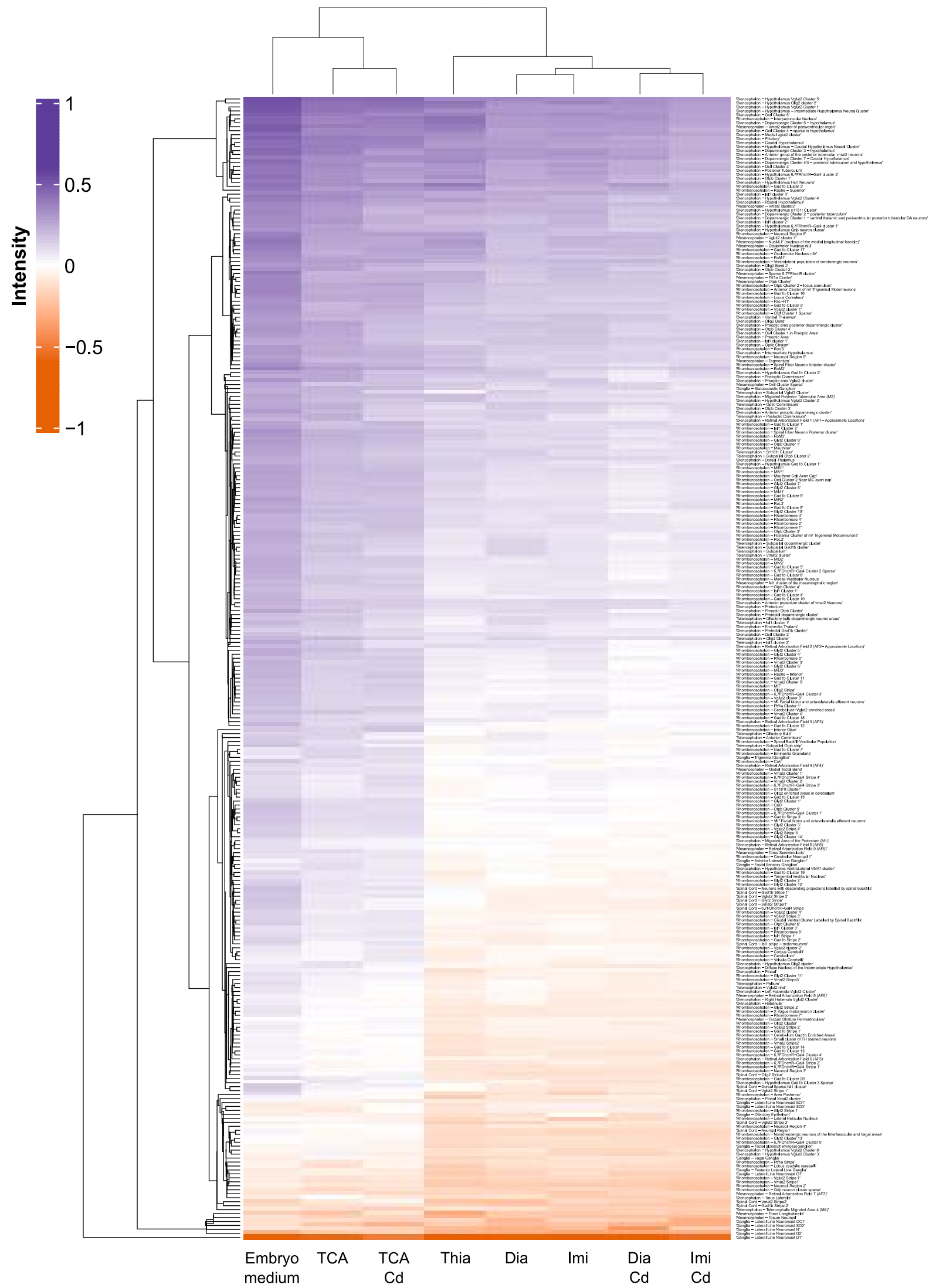

Figure 59: Neuronal activity in the different brain regions during avoidance. The heat map shows the similarities and dissimilarities in neuronal activity of 289 different brain regions for the different treatments embryo medium $(n=14)$, TCA ( $n$ $=14)$, diazinon $(n=13)$, and imidacloprid $(n=11)$, thiacloprid $(n=8)$, and the cadmium-treated fish $(n=11)$. Here the names of the brain regions are included. 
TCA

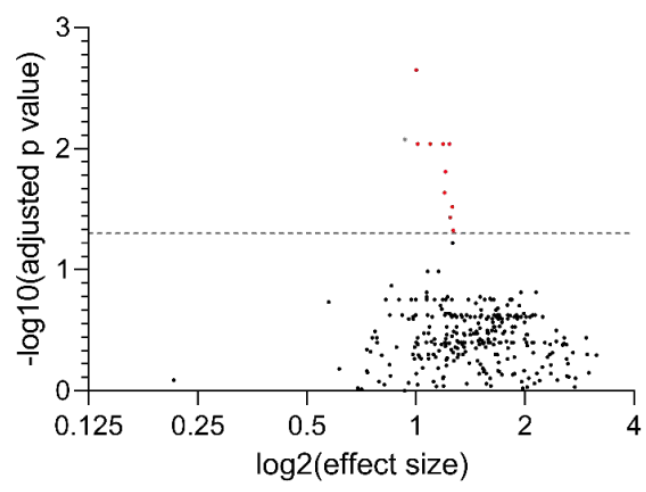

Diazinon

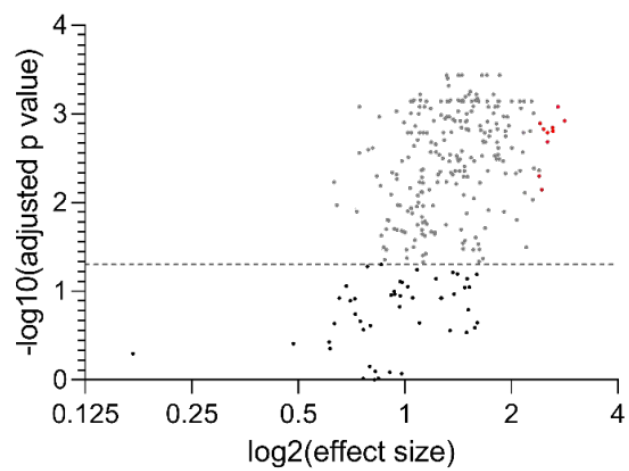

Imidacloprid

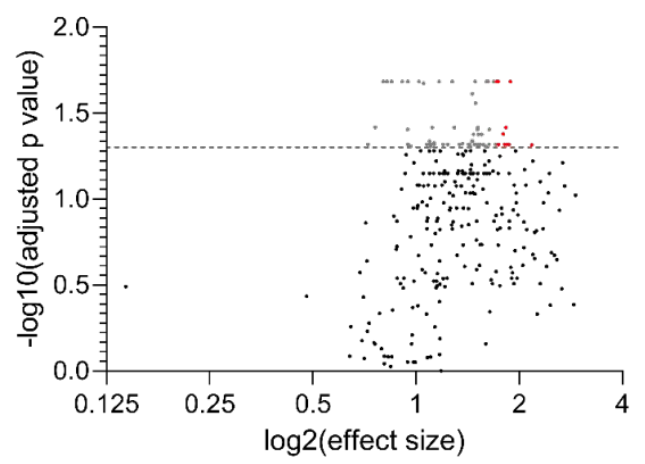

Figure S10: Volcano plots based on the adjusted $p$ values calculated for all 289 brain regions. Statistically significant brain regions are highlighted in grey, while non-significant regions are shown in black. Among the significant regions, the top ten were selected based on effect size. These are highlighted in red. The dashed line represents the cut-off for significance $(p=0.05)$. 


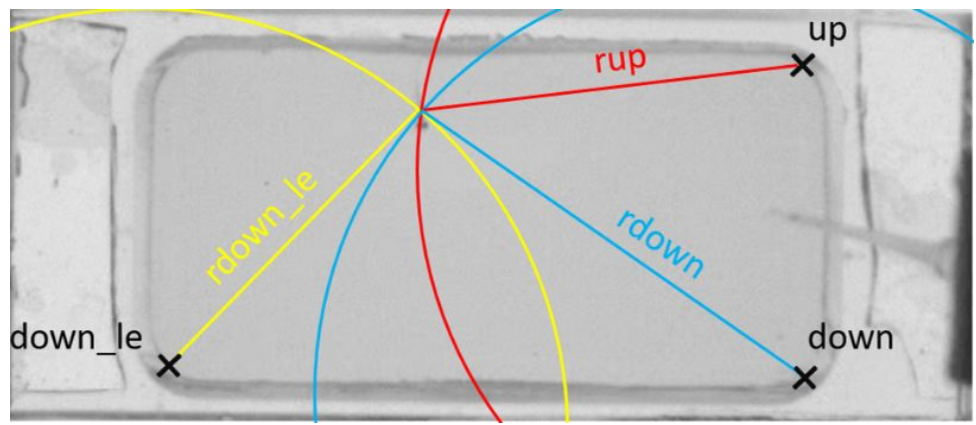

Figure S11: Exact position tracking based on triangulation. The static points (up, down, down_le) were subsequently defined to determine the fish's $\mathrm{x}$ and $\mathrm{y}$ position in the chamber. rup, radius up; rdown, radius down; rdown_le, radius down left; down_le, down left.
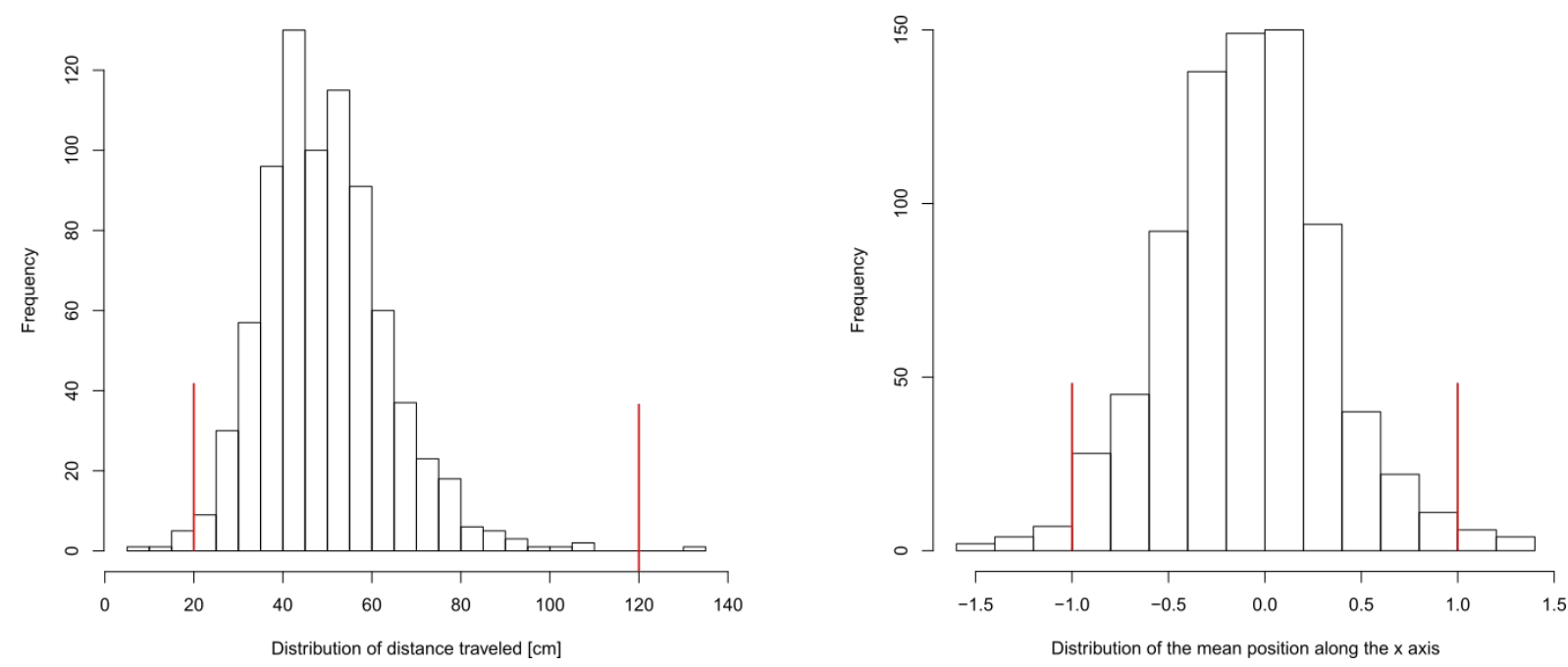

Figure S12: Data inclusion based on the histograms of the distance travelled (left) and the mean position of 727 fish (right). The red lines show the $1 \%$ and the $2.5 \%$ quantiles for the distance travelled and the mean position, respectively. 
Table S4: Sample sizes at different points of data analysis. Number of individuals tested in the behaviour assay (initial N) and the number of individuals left after application of the acceptance criteria. Sample size after the third criterion equals the sample size used for further analyses.

\begin{tabular}{|c|c|c|c|c|c|}
\hline & & Initial N & First criterion & Second criterion & Third criterion \\
\hline Embryo medium & & 30 & 30 & 30 & 30 \\
\hline \multirow[t]{2}{*}{ TCA } & $10 \mathrm{mM}$ & 32 & 32 & 32 & 31 \\
\hline & $100 \mathrm{mM}$ & 20 & 20 & 20 & 19 \\
\hline \multirow[t]{4}{*}{ Diazinon } & $0.1 \mathrm{uM}$ & 34 & 34 & 34 & 33 \\
\hline & $1 \mathrm{uM}$ & 30 & 30 & 30 & 29 \\
\hline & $10 \mathrm{uM}$ & 38 & 38 & 38 & 37 \\
\hline & $100 \mathrm{uM}$ & 30 & 30 & 30 & 30 \\
\hline \multirow[t]{4}{*}{ Dimethoate } & $0.1 \mathrm{uM}$ & 30 & 30 & 30 & 29 \\
\hline & $1 \mathrm{uM}$ & 31 & 31 & 31 & 31 \\
\hline & $10 \mathrm{uM}$ & 31 & 31 & 30 & 28 \\
\hline & $100 \mathrm{uM}$ & 31 & 31 & 31 & 31 \\
\hline \multirow[t]{4}{*}{ Imidacloprid } & $0.1 \mathrm{uM}$ & 30 & 30 & 30 & 30 \\
\hline & $1 \mathrm{uM}$ & 30 & 30 & 30 & 30 \\
\hline & $10 \mathrm{uM}$ & 31 & 31 & 31 & 31 \\
\hline & $100 \mathrm{uM}$ & 30 & 30 & 30 & 28 \\
\hline \multirow[t]{4}{*}{ Thiacloprid } & $0.1 \mathrm{uM}$ & 30 & 30 & 29 & 29 \\
\hline & $1 \mathrm{uM}$ & 30 & 30 & 30 & 29 \\
\hline & $10 \mathrm{uM}$ & 30 & 30 & 29 & 29 \\
\hline & 100 uM & 31 & 31 & 30 & 29 \\
\hline \multirow[t]{4}{*}{ Pirimicarb } & $0.1 \mathrm{uM}$ & 31 & 31 & 30 & 30 \\
\hline & $1 \mathrm{uM}$ & 30 & 30 & 30 & 30 \\
\hline & $10 \mathrm{uM}$ & 30 & 30 & 30 & 30 \\
\hline & $100 \mathrm{uM}$ & 30 & 30 & 30 & 29 \\
\hline \multirow[t]{4}{*}{ Methomyl } & 0.1 uM & 30 & 30 & 30 & 28 \\
\hline & $1 \mathrm{uM}$ & 30 & 30 & 30 & 29 \\
\hline & $10 \mathrm{uM}$ & 31 & 31 & 31 & 30 \\
\hline & $100 \mathrm{uM}$ & 30 & 30 & 30 & 29 \\
\hline
\end{tabular}


Table S5: Sample sizes for cadmium treated fish at different points of data analysis. Number of individuals tested in the behaviour assay (initial $\mathrm{N}$ ) and the number of individuals left after application of the acceptance criteria. Sample size after the third criterion equals the sample size used for further analyses.

\begin{tabular}{rccccc}
\hline & Initial N & First criterion & Second criterion & Third criterion \\
\hline TCA Cd & $10 \mathrm{mM}$ & 31 & 31 & 31 & 27 \\
Diazinon Cd & $10 \mu \mathrm{M}$ & 36 & 36 & 36 & 32 \\
Imidacloprid Cd & $10 \mu \mathrm{M}$ & 32 & 32 & 32 & 25 \\
\hline
\end{tabular}

a

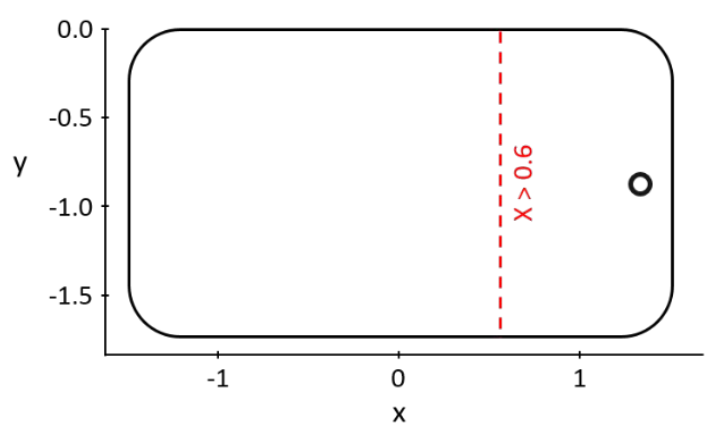

b

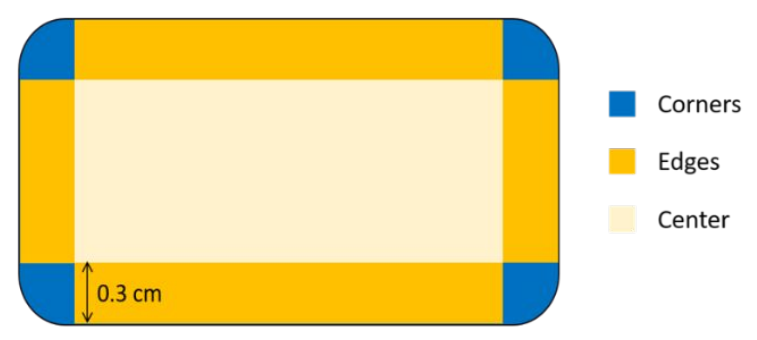

Figure S13: Illustrations showing the coordinate system that was fit to the chamber (a) and the three zones that were defined for the random walk model (b). $X$ values larger than 0.6 (dotted line, a) are considered to be in the chemical zone. The circle in $A$ shows the position of the inlet. 


\section{Biased random walk model}

In order to test whether the swimming behavior of zebrafish can be simulated in a way that it recapitulates the observed behaviors, we developed a simple biased random walk model, which was based on the probability distributions of the two basic swimming parameters turn angle size and velocity. Such a model helps to better understand how a larva adapts to an environmental threat, and allows for the identification of sensitive metrics. In addition to turn angle size as well as velocity, the form and limits of the chamber were included in the calculations. Thus, we accounted for the fact that turn angles as well as velocities differ depending on the fish's position in the chamber. Therefore, the chamber was divided into three zones: the center zone, the edges and the corners (SI, Figure S13b). The size of these zones was defined, such that the mean simulated time spent in this area matches the observations of the control fish. The size of the zones was kept the same for the fish tested with chemicals. Velocity and turning angles were measured for the control fish and probability distributions for both parameters were constructed based on these measurements. The probability distribution for velocity was modeled by the gamma function $\left(r^{2}=0.95\right)$, while the turn angles in the edge and center, and the corners were modeled with an exponential and a Cauchy distribution, respectively $\left(r^{2}=0.99\right)$.

For the control fish, the starting point was chosen randomly, then in each time step a value was chosen for velocity and turning angle randomly from the probability distributions and the next position for the fish calculated. This was repeated until the end of the simulation. For fish tested with insecticides, the simulations were performed with the same rules, except that the area with $\mathrm{x}$ coordinate larger than 0.6 was defined as a chemical zone (SI, Figure S13a). When the fish was present in this area ( $x$ coordinate of fish > 0.6), the value for the parameters turn angle and the velocity were chosen using the probability distributions that simulate the action of the chemical (SI, Figure S14). To account for the bias towards a certain zone in the chamber, bias-correction was performed by dividing the chamber into 10 equally sized groups along the $x$ axis. For these groups, the ratio of positions in the top and bottom edge zone was calculated and adjusted according to the experimental ratio. 

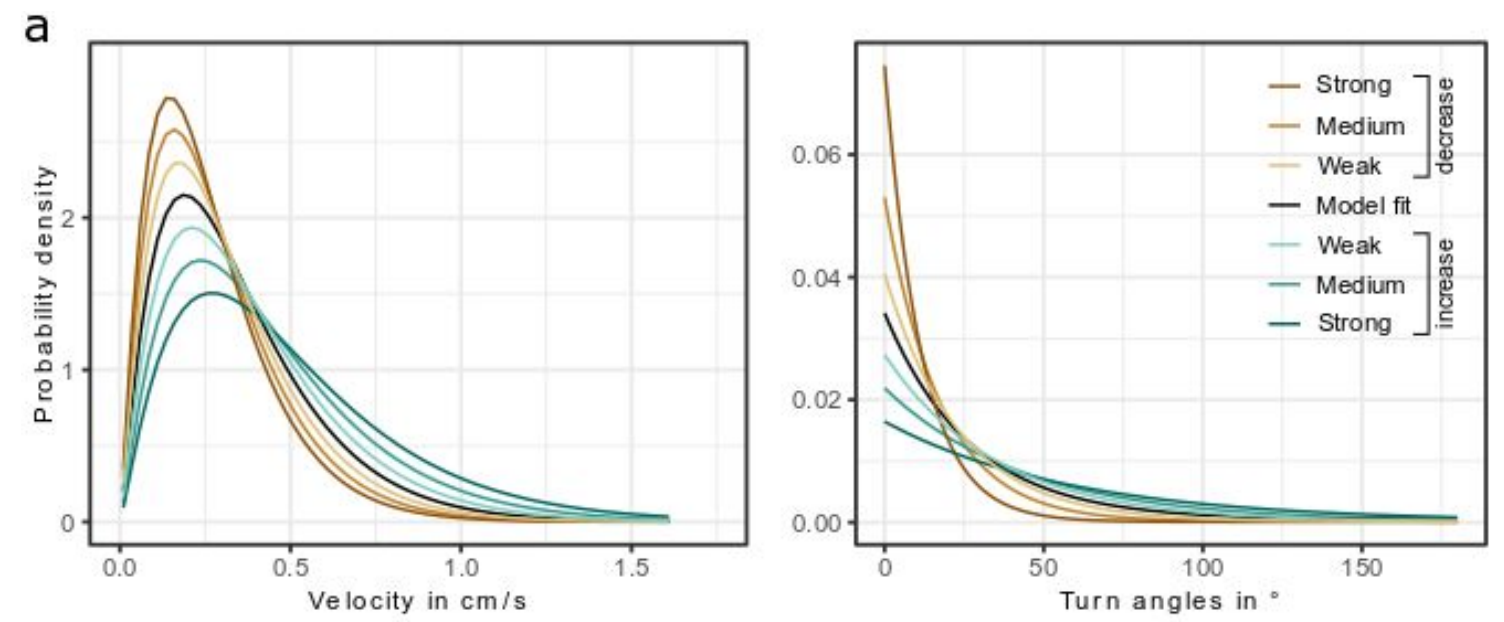

\section{b}
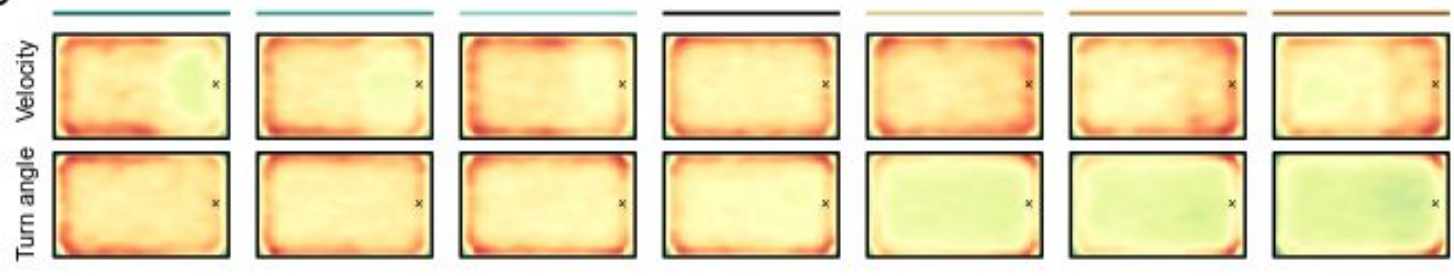

C

Embryo medium

TCA
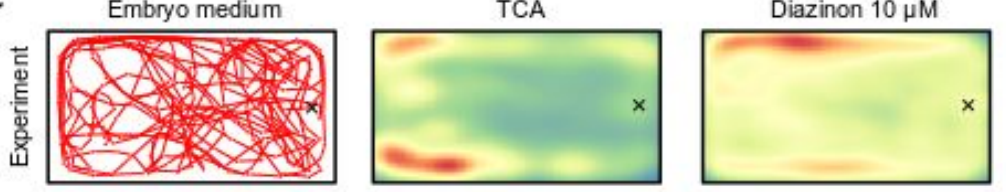

Imidacloprid $10 \mu \mathrm{M}$

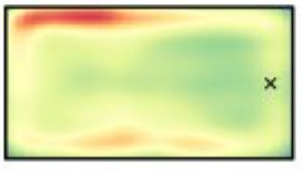

Density
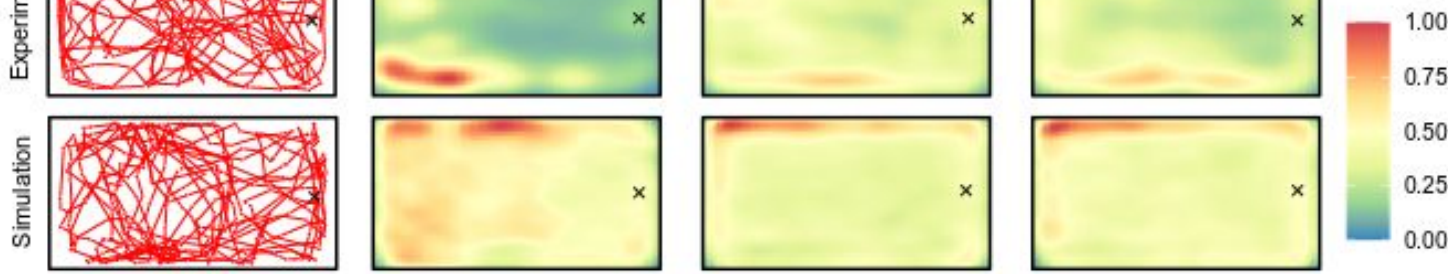

0.50

0.25

0.00

Figure S14: Simulation of trajectories with the random walk model. (a) Probability distributions for the velocity in $\mathrm{cm} / \mathrm{s}$ (left) and the turn angle size in degree (right). The model fit (black) represents the distribution of the experimental data. The brown and green curves show three different scenarios of gradually decreased or increased velocity or turn angle size in the chemical zone. The respective heatmaps plotting the position density of the simulated fish for the different scenarios are shown in (b). An increase in velocity as well as turn angle size led to a shift of positions away from the chemical zone, while a decrease of both parameters shifted positions towards the inlet. In (c), the comparison between the experimental and the simulated (bias-corrected) trajectories after the injection of the chemical is shown. For embryo medium, the individual positions were plotted on which the heatmaps are based. The model was run with 100 iterations. 